\title{
Applicability of the Theory of Phonology to the Sound System of Tiv Language
}

\author{
${ }^{1}$ Kaan, Aondover Theophilus, ${ }^{2}$ Yoo, Angwe Sebastine \\ ${ }^{I}$ Department of English, Federal University, Dutsin-ma, Katsina State, Nigeria. \\ ${ }^{2}$ Department of Linguistics, University of Nigeria, Nsukka.
}

\begin{abstract}
This descriptive study is an appraisal of the applicability of the theory of phonology to the sound system of Tiv language. It examines the phonology of Tiv, to see its conformity to the universal patterning of sounds in human language. In doing this, the study employs the descriptive method of research by observing the native speakers of the language and describing how the theory of phonology applies to Tiv language, using the phoneme theory, the distinctive features theory and the tone/pitch contours theory as testing grounds. The findings reveal that the theory of phonology is essential to the formation and combination of sounds in Tiv. It concludes that Tiv language, just like any other language, has its phonology derived from the universal phonetic application of phonological rules, in line with acceptable phonological theories.
\end{abstract}

Key words: theory, phonology, phoneme, pitch, Tiv language

\section{Introduction}

Language as a medium of communication has been a distinguishing factor between human beings and animals, a feature which defines humans as rational and a tool in the hands of man to subdue even animal brutality. Tiv language is part of the Southern Bantiod -Tiviod family as well as a branch of the Benue-Congo and ultimately the Niger-Congo family. It is spoken by over two million people in Nigeria, with a few speakers in Cameroon. In Nigeria, Tiv speakers are found majorly in Benue State, the language is also spoken widely in Taraba, Nasarawa, Plateau and Cross River States.

A lot of sounds are generated by human beings and animals and to some extent, inanimate objects. Sometimes these sounds come in form of noises and as such, cannot be associated with human sounds that generate meaning. When human beings speak, they form sounds and these sounds generate meaning that can only be realized through phonological constituents. And this is achieved when we apply the universal properties of natural language sound system. In order to derive meaning from human language, we must refer to human speech sounds and this is where the study of phonology and its attendant theories come to the fore.

Although phonology is broad, it has its roots from phonetics which Akmajian et al (2003:66) say, is concerned with how speech sounds are articulated in the vocal tract, as well as with the physical properties of the sound waves generated by the vocal tract. This implies that phonetics is general while phonology is language specific. This further explains why we can talk of the phonology of Igbo, Yoruba, Hausa, Tiv, English etc. This shows therefore, that it is only human beings that can produce sounds that can be organized into meaningful patterns in specific languages.

Agbedo (2000:59) also sees the organization of speech sounds into meaningful utterance as a fundamental function of human languages when he considered the field of phonology as " $\ldots$ functional phonetics in the sense that it is concerned with the ways in which the sounds and prosodic features defined by phonetics are actually used in given natural languages".

The theory of language is applicable to every conventional human language and this is what creates a system of meaning through some phonological rules, with the help of the sound combination of the language. Lyons (1980:21) supports this view when he posited that "phonology considers speech sounds independently of their paradigmatic apposition and syntagmatic combinations in particular languages and that phonology is the level at which linguists describe the sounds of a particular language".

From the foregoing, it is pertinent to deduce that for any human language to enable its sound system to generate meanings there must be an application of the universal principles of phonology based on the theory of phonology. This is so, because, the theory of phonology is operational at both the segmental and suprasegmental levels of language. To relate the theory of phonology to Tiv language and how it functions in the language therefore, we shall use some of the sub-theories of phonology - phoneme theory, distinctive features theory and tone/pitch contours theory as testing grounds. 


\subsection{Statement of the Problem}

The phonology of any conventional human language is enhanced by the word formation process in that language based on its sound system. In describing the phonology of a given language therefore, the orthography of that language becomes the spring-board for effective analysis, even though orthography and phonology are different realms of linguistic concerns.

The lack of uniformity in some cases and lack of delineation in other cases in the written form of Tiv language sometimes create a problem for its phonemic representation. Similarly, in the spoken aspect of Tiv language, sound contrasts are not significantly due to differences between phonemes but by supra- segmental features like intonation and pitch.

This study thus, sets out to examine the sound system of Tiv language by analyzing the sound combinations in the language with reference to universal phonetic and phonological properties, in order to ascertain the extent of conformity of Tiv phonological system to acceptable phonological rules.

\subsection{The Phoneme Theory}

\section{Literature Review}

In establishing the theory of phoneme, it is pertinent to generally consider a phoneme as the smallest meaning unit of sound that can delineate meanings in any given language. O'Connor (1973:66) as cited in Agbedo (2000:63) sees phoneme as "... the functional units of which sounds are realizations ..." Phoneme, according to Daniel Jones as quoted in Agbedo (2000:63) can be looked at “... as a family or group of acoustically or articulatorily related speech sounds that never occur in the same phonic environment".

Agbedo (2000:64) on his part posited that "a phoneme is a speech sound that is distinctive in a given language". He further stated that the prominent quality of distinctiveness forms the basis for establishing phonemes in a given language.

In every language, there is the possibility of finding restriction on the sequence of phonemes that are functional in the language. Even though all languages draw from a pool of universal linguistic features, individual languages make use of different groups of features that constitutes their phonemes. It is in light of the above that the postulation of Akmajian et al (2003:118) that “... phonemes of all languages may be describe in terms of differing subsets of the universally available set of distinctive features" seems to be a rallying point for our study.

Roach (2000:38-39) observed that when we speak:

We produce continuous stream of sounds... we divide this stream into small pieces that we call segments..., in the alphabet we have five letters that are called vowels: 'a', 'e', 'i', 'o', 'u'. If we choose the right context, we can show how substituting one letter for another will change meaning thus, pit, pet, pat, pot and put.

He went further to point out that we can apply the above principle of word formation to the sound constituents by substituting the following vowels for another; i, e, æ, $\Lambda, \mathrm{D}$, u in words as follows: 'pit'/pit/, 'pet' /pet/, 'pat' /Pæt/, 'pot'/PDt/ and 'put' (Put).

The above illustration serves to buttress what Gimson (1980:49) says about the possibility of establishing the phoneme of a language by the process of commutation of minimal pairs, that is, pairs of words that are different only in one sound segment. He equally sees phoneme as "... abstract linguistic units which will include sounds of different types ..."

From the foregoing, it is safe to posit that there is an abstract set of units as the basis for our speech sounds - the phonemes are abstract. However, there are slightly different ways in which we make sounds in languages to represent these phonemes. Whatever we decide to be the number of phonemic symbols in a language, we make the same number of phonemes to exist in that language. Although in some cases, we may have phonemes that are made up of two characters. For instance, in English language, the phoneme $/ \mathrm{t} f /$ consists of two characters ( $t$ and $\int$ ) as in 'church'.

In the study of phonology therefore, the phoneme theory is used to analyze what the restrictions and regularities are in a particular language and this is usually achieved by studying the syllable of the language.

\subsection{The Distinctive Features Theory}

This theory was developed by N.S. Trubetzkoy and the Prague school of linguistics. In order to understand the theory of phoneme and the theory of phonology generally, the distinctive features theory becomes a means of examining the similarities and differences in a given phonetic string. Agbedo (2000:66) opined that " $\ldots$ this method is partly phonological because it considers the functional properties of phonemes, and partly phonetic because it considers the articulatory and acoustic differences between phonemes in the inventory". He went further to give examples in English of /p, b, m/. /t, d, n/ and /k, g, $\eta /$, noting the differences between them, which he said can be accounted for in terms of three general acticualtory features - oral Vs nasal, fortis Vs lenis and place of articulation (labial, alveolar, velar). 
Hawkins (1984:43) maintains that the distinctive features theory determines phonetic features that are significant in a language and those that are not significant towards the realization of a theory of phonology. He notes further that it also functions in stating phonological regularities in terms of rules. He also asserts that distinctive feature serves to distinguish phonemes such as /z/ and /s/ in 'zip' and 'sip' as well as /f/ and /v/ in leaf and leave.

From the position of Hawkins, it therefore portends that the distinctive feature is a significant phonetic property of human language that plays a crucial role in the statement of phonological rules by distinguishing phonemes from one another.

Akmajian et al (2003:125) also support Hawkins' view when they said:

The distinctive features are exactly those that permit an insightful description of the vowel change. The vowel $/ \Lambda /$ has the features [+ back] and [- high], the vowel /i / has the features [- back] and [+ high] and the consonants $/ \mathrm{d}, \mathrm{t} \int, \mathrm{j}$, л, $\mathrm{J} /$ also have the features [- back] and [+ high]. Thus, the features of the vowels and the preceding consonants tell us that an assimilation process is at work.

They concluded that distinctive features allow the exact nature of the assimilation process between two adjacent phonological segments to be explicitly expressed.

This short but insightful review on the distinctive features has established that distinctive features theory is a mechanism that is derived from the properties of the phonological rules of world's languages.

\subsection{Tone/Pitch Contours Theory}

The tone/pitch theory started in Britain by Palmer (1924) who introduced the 'tone-unit' or 'tonetic' approach. This approach was based on a range of phonological units that are in a hierarchical relationship. This presupposes that tone is carried by the 'tonic syllables' in a phonological structure-the most prominent syllable. For example, import (noun)/'imps:(r)t/and /im'po:(r)t/ verb.

Pike (1945) however evolved another approach to the tone/pitch theory in the United States which he called 'contrastive pitch levels' that was based on 'pitch phonemes'. This approach basically described a series of movement from one level to another. For instance, 'untouchable' - un tou cha ble (L H L L). Here, the pattern is that the pitch is realized by low tone followed by high tone and tow low tones and not by one prominent syllable. The 'pitch phoneme' theory was later embraced by scholars like Trager and Smith (1951) while scholars like Kingdon (1958), O‘Connor and Arnold (1962) and Haliday (1967) championed Palmer’s approach.

The two approaches gradually became elaborate and cumulatively led to the developments in the tone/pitch theory. While Trager (1964) extended Pike's approach, O‘Connor and Arnold (1973) expanded on Palmer's approach. However, the modern day approach to the study of tone/pitch contours is more theoretized in Ladd (1996) and Cruttenden (1997), whose works are based on Palmer's model, with an encapsulation of Pike's approach.

Tone, to Bolinger (1951: 199) is "the subjective sensation and the objectively measureable fundamental frequency of a speaker's voice..." He stressed that those whose languages are tonal should always take into consideration the linguistic importance of tone in the production of sounds in a language.

Roach (2000:150) notes however, that no definition of tone is completely satisfactory. He observed that “... but any attempt at a definition must recognize that the "pitch' of a voice plays the most important part". He stressed further that pitch is identified and described in terms of 'high and 'low' as arbitrary choices for endpoints of the pitch scale.

What can be inferred from the above postulation therefore is that, for the realization of speech sounds and their meanings in tone languages, pitch becomes the underlying factor. And that for pitch differences to be linguistically significant it should be used to refer to an auditory sensation of the speaker that can be experienced by the hearer.

Pitch according to Agbedo (2000:57) is "the acoustic result of the speed of the vibration of the vocal cords". The acoustic production of sounds (higher or lower) is usually as a result of the vibration of the speed of the vocal cords. The higher the speed of the vocal cords the higher the pitch. One thing worthy of note is that pitch differs from language to language.

Onuigbo (1996) observed that the rise and fall in the pitch of the voice is important in the spoken aspect of language. To him, this, among other factors, conveys the attitude of the speaker towards the listener or to what is being said. He asserts that:

When we speak, the voice pitch changes; becomes high or low depending on the meaning the speaker intends... if there are no such changes, the speech would sound monotonous or even meaningless... tone is used meaningfully in all Nigerian languages ... to distinguish words of the same spelling in many Nigerian languages... (94) 
From the review of literature so far under the theoretical conceptions of the phoneme theory, the distinctive features theory and the tone /pitch contours theory, it is evidently clear that universal principles of linguistics apply to languages of the world generally, and this include Nigerian languages. In this regard, Tiv language cannot be an exception. It is in this light that this study is proposed.

\section{Methodology}

This study is essentially a descriptive study probing into the applicability of the universal theory of phonology to the sound system of Tiv language. It does not claim to describe all the aspects of the theory of phonology but only makes a survey.

Basically, the observation method was used to elicit data for this study. However, to complement the information gathered through observation, the study made use of secondary sources derivable from books and other library materials especially available materials on the phonology of Tiv language.

\section{Analysis of the Applicability of the Theory of Phonology to the Sound System of Tiv Language.}

\subsection{The Phoneme Theory}

As earlier noted by O'Conner (1973) a phoneme is “... the functional units of which sounds are realization ..." The Tiv language just like other languages has functional units of sounds that generate meaning. Just as phonemes serve to contrast meaning between similar sounding words in most languages, the Tiv language too applies this phonological rule to generate meaning. For instance, the following words in Tiv are similar except for one sound segment that occurs at word initial position.

Ken, Jen, Sen, hen /k, dz, s, h, /

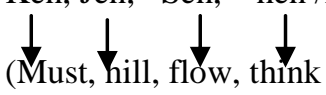

Hime, time $/ \mathrm{h}, \mathrm{t} /$

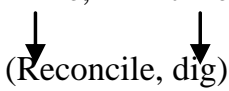

Bam, tam, kam, nam, fam /b, t, k, n, f, /

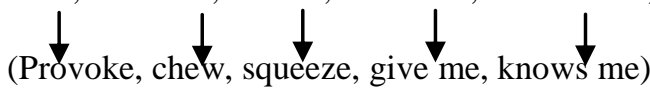

Bume, Hume, kume, tume /b, h, k, t, /

(Fơlish, fäint, poưnd, thrust)

Naha, kaha, laha /n, k, 1/

The contrastive application of the speech sounds /k, dz, s, h, b, t, n, f, l / to the Tiv language as shown above indicates that they are phonemes in the language and they can effect a change in the meaning of words. The contrastive nature of phoneme in Tiv language sometime makes it possible for the contrast to occur in the middle of a word. This contrast is feasible in both consonant and vowel sounds. For example,

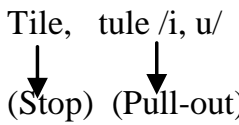

Ivo, iho, /v, h/

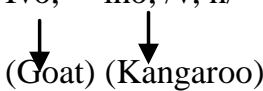

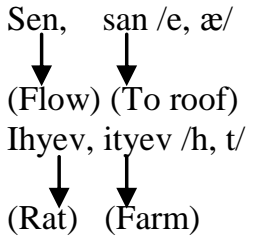


In the same vein, the contrast may occur at the end of a word and this is as well applicable to both consonants and vowels. Examples are:

Ikyume, (Kind of snake) (Puberty hair)

Gbev, gbem /v, m/

(Motuse) (Anthill)

$\mathrm{Kpan}, \mathrm{kpam} / \mathrm{n}, \mathrm{m} /$

$\stackrel{1}{\frac{1}{d}} \stackrel{1}{\text { Slave) (Gorgeous) }}$

From the above examples, it is clear that Tiv language has a good linguistic base for the establishment of phonemes through minimal pairs or words that are different only in one sound segment. This is so because they occupy the same phonetic environment and have the same quality of distinguishing different words.

\subsection{The Distinctive Features Theory}

The distinctive features theory as noted earlier is a method for examining the similarities and differences in a given phonetic string. To describe sounds in Tiv language, the use of this theory of phonology becomes inevitable because we try to draw out as many features as possible which can be found in them. The basic thing to do is to mention those features by which the difference is noticed. The distinctive features can be indicated by the use of binary symbols plus (+) where it is present and minus (-) where it is absent.

Distinctive features in Tiv language as noted by Shoja (2010) can occur as a result of the manner and place of articulation. For example:

Vine and kine /v/ is + labio-dental while /k/ is + velar

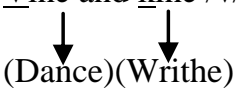

$\underline{\text { Gafa and }}$ dafa /g/ is + velar while /d/ is + alveolar

(Eagle) (Gtinea corn porridge)

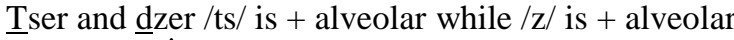

(Mutiply)(Tie)

Kwaghdoo and kpadoo $/ \mathrm{kw} /$ is + palatal while $/ \mathrm{kp} /$ is + labio velar

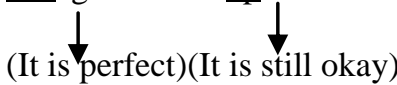

Pase and mase $/ \mathrm{p} /$ is + bilabial while $/ \mathrm{m} /$ is + nasal

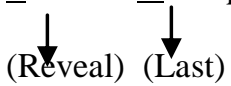

Voicing as a distinctive feature of phonology can also cause contrast in Tiv language. For example:

Pam and bam: while /p/ is -voiced /b/ is +voiced

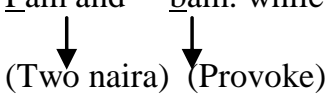

Telegh and dyelegh /t/ is - voiced while /d/ is +voiced<smiles>CC(C)(C)NC(C)(C)[Ge]</smiles>

Kor and gor $/ \mathrm{k} /$ is -voiced while /g/ is + voiced

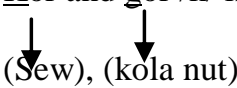


In the first example, while the bilabial sound /p/ is voiceless, the bilabial sound $/ \mathrm{b} /$ is voiced. In example two, while the alveolar sound /t/ is voiceless, the alveolar sound /d/ is voiced. Similarly, in example three, while the velar sound / $/ \mathrm{k}$ is voiceless, the velar sound /g/ is voiced. This gives us the analysis in binary notation as - voiceless and + voiced.

From the above discussion, it is pretty clear that the phonemic and contrastive features theories of phonology can be applicable to the Tiv language at the segmental level.

\subsection{Tone/pitch Contours Theory}

Like many other African languages, the Tiv language uses pitch to distinguish two or more similarities in terms of consonants and vowel structures. When pitch is used for contrasting of such words, it is referred to as tone contours.

In Tiv language, the functionality of high and low tones go a long way in showing the differences between lexical items that are same in structure. For instance:

Tár - (high) and tàr- (low)

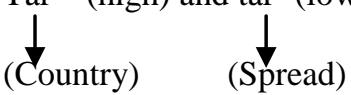

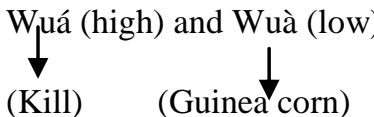

Yáv (high) and yàv (low)

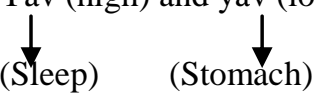

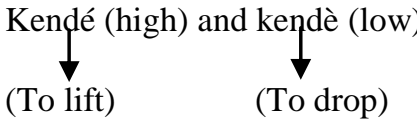

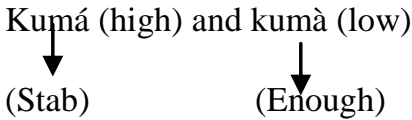

Udu (2009) also agrees that Tiv language makes use of tones significantly. According to him, word meaning and other grammatical categorization such as tense and plurality are dependent on pitch. He identified three main tone types in Tiv language. These include high, mid and low. He gave examples as follows:

High tone; ná (to give), tá (to hit), wá (to insert), ayém (race), shá (up)

Mid tone; sēndē (to execute), nēngē (to see), nāhān (so), zēndē (journey)

Low tone; ishàn (star), lyèmèn (slippery) ànyàm (tiger), màà (build)

He went further to state that there is another complex type of tone which according to him is partly high and partly low. His examples include:

Tòr(king), tór (pestle), tŏr (kind of mouse), tőr (eaves), kāhā (different), káhā (to till), káhá (to turn).

He concludes by giving examples as to how tone marks plurality in Tiv language especially with names of animals.

$\begin{array}{lc}\text { (Singular) } & \text { (Plural) } \\ \text { Îvō (goat) } & \text { ívó (goats) } \\ \text { iyôngò (sheep) } & \text { íyôngō (sheep) } \\ \text { ìgò (pig) } & \text { ígō (pigs) } \\ \text { ìwā (dog) } & \quad \text { íwyá (dogs) }\end{array}$

From the above analysis and examples, we can conclude that tonality is also a phonological feature in the Tiv language.

\section{Summary of Findings}

The study examined the applicability of the theory of phonology to the sound system of Tiv language. It reveals that phonemes are marked in the phonology of Tiv, and they bring about a change in the meaning of words in the language. The findings also show that distinctive features of phonology serve to contrast similarities and differences in Tiv language. For tone and pitch, the study indicates that tone is a characteristic of the Tiv language because the rise and fall of tone through pitch of the voice determines shades of meaning of 
words. It is also discovered from the study, that even grammatical categorizations like tense and plurality are dependent on pitch to explicate meaning in Tiv language.

\subsection{Conclusion}

The study has shown that the application of the theory of phonology to the sound system of Tiv language is uncontestable. Through this application of the universal principles of language, Tiv phonology has proved to be in tune with the operational tenets of the phoneme theory, the distinctive features theory as well as the tone/pitch contours theory which are the base line for any phonological analysis.

\section{References}

[1]. Agbedo, Chris. U. (2000). General Linguistics: An Introductory Reader. Nsukka: ACE.

[2]. Akmajian et al (2003). Linguistics: An Introduction to Language and Communication, New Delhi: Prentice-Hall.

[3]. Bolinger, D (1951). 'Intonation: levels Vs configuration', Word, Vol. 7.

[4]. Cruttenden, A. (1997). Intonation, $2^{\text {nd }}$ ed, Cambridge: Cambridge University Press.

[5]. Gimson, A.C. (1980). An Introduction to the Pronunciation of English, London: Edward Arnold Publishers Limited.

[6]. Halliday, M.A.K (1967) Intonation and Grammar in British English. The Hague: Mouton.

[7]. Hawkins, P. (1984). Introducing Phonology. London: Routlege.

[8]. Kingdom, R. (1958) .The Groundwork of English Intonation. London: Longman.

[9]. Ladd, D.R. (1996). Intonational Phonology. Cambridge: Cambridge University Press.

[10]. Lyons, J. (1986) .Introduction to Theoretical Linguistics. Cambridge: Cambridge University Press

[11]. O'Connor, J.D. and Arnold, G.F. (1973). Intonation of Colloquial English $2^{\text {nd }}$ ed, London: The Longman.

[12]. O’Connor, J.D. (1973b). Phonetics. Middlesex: Penguin Books.

[13]. Palmer, H.E (1924). English Intonation with Systematic Exercises. Cambridge: Heffer.

[14]. Palmer, F.R. (1976). Semantics: An Outline. Cambridge: C.U.P

[15]. Pike, K.L. (1945) .The Intonation of American English. Ann Arbor, MI: University of Michigan Press.

[16]. Roach, P. (2000). English Phonetics and Phonology. ( $3^{\text {rd }}$ low price edn). Cambridge: Cambridge University Press.

[17]. Shoja, A. (2010) .Tiv Language in Practice: A Descriptive Approach Katsina-Ala: Gold Ink Company.

[18]. Trager, G.L. and Smith, H.L. (1951). An Outline of English Structure. Washington, DC: American Council of Learned Societies.

[19]. Trager, G.L. (1964). “The Intonation System of American English' in D. Abercrombie et al. (1964) pp. 266.70.

[20]. Trubetzkoy, N.S. (1939) .Principles of Phonology. California: University of California Press.

[21]. Udu, T.T. (2009) .Tiv Language: A Reference Book. Katsina-Ala: Gold Ink Company. 